\title{
Effect of dexamethasone on extracellular secretion of cystatin $C$ in cancer cell lines
}

\author{
CHIKA YAMAWAKI $^{1}$, MINORU TAKAHASHI $^{1}$, KOHJI TAKARA $^{1}$, MANABU KUME $^{2}$, \\ MIDORI HIRAI $^{2}$, HIROYUKI YASUI ${ }^{3}$ and TSUTOMU NAKAMURA ${ }^{1}$ \\ ${ }^{1}$ Department of Pharmaceutical Health Care, Faculty of Pharmaceutical Sciences, Himeji Dokkyo University, \\ Himeji, Hyogo 670-8524; ${ }^{2}$ Department of Pharmacy, Kobe University Hospital, Kobe, Hyogo 650-0017; \\ ${ }^{3}$ Department of Analytical and Bioinorganic Chemistry, Kyoto Pharmaceutical University, Kyoto 607-8414, Japan
}

Received September 6, 2012; Accepted October 9, 2012

DOI: $10.3892 / b r .2012 .21$

\begin{abstract}
The aim of the present study was to investigate dexamethasone (DEX)-induced secretion of cystatin C (Cys C) and the effect of cisplatin (CDDP) and 5-fluorouracil (5-FU) on Cys $\mathrm{C}$ secretion in human cancer cell lines. KYSE150, A549 and Caki-2 human cancer cell lines were cultured on plastic dishes and treated with DEX (100 nM) for 24, 48 and $72 \mathrm{~h}$. KYSE150 cells were co-treated with DEX, CDDP $(10 \mu \mathrm{M})$, and 5-FU $(2 \mu \mathrm{M})$. The effects of DEX, CDDP and 5-FU on cell viability were evaluated. Results showed Cys $\mathrm{C}$ secretion levels in the culture medium of DEX-treated KYSE150 cells to be 1.8- to 2.3-fold higher compared to those in the culture medium of control cells. A similar tendency was observed in A549 cells at all the time points, whereas a significant increase in the Cys C secretion by Caki-2 cells was observed only $24 \mathrm{~h}$ after DEX treatment. Regarding KYSE150 cells, the secretion of Cys C was also enhanced by co-treatment of CDDP or 5-FU with DEX, although it was not affected by the co-administration of DEX and mifepristone, a glucocorticoid receptor antagonist. At concentrations that are typically used in esophageal cancer chemotherapy, CDDP and 5-FU demonstrated a moderate level of cytotoxicity in KYSE150 cells in contrast to DEX. These findings suggested that DEX has the potential to enhance the extracellular secretion of Cys $\mathrm{C}$ in esophageal cancer cells, possibly due to the transcriptional regulation mediated by glucocorticoid receptor activity.
\end{abstract}

\section{Introduction}

Cystatin C (Cys C) is a non-glycosylated cationic 13.3-kDa protein belonging to the cystatin superfamily of cysteine protease

Correspondence to: Professor Tsutomu Nakamura, Department of Pharmaceutical Health Care, Faculty of Pharmaceutical Sciences, Himeji Dokkyo University, 7-2-1 Kamiohno, Himeji, Hyogo 670-8524, Japan

E-mail: tsutomun@gm.himeji-du.ac.jp

Key words: cystatin C, dexamethasone, cisplatin, 5-fluorouracil, esophageal cancer, glucocorticoid receptor inhibitors (1-3). Cys C is produced by nucleated cells and is secreted into the blood at a constant rate (1-3). It is freely filtered through the glomerular membrane, completely re-absorbed and then catabolized in the proximal tubular cells (1-3). Thus, similarly to creatinine, the biological fate of Cys $\mathrm{C}$ is a good endogenous marker of the glomerular filtration rate (GFR).

In patients with esophageal cancer, cisplatin (CDDP) is used as a neoadjuvant or as a post-operative adjuvant chemotherapy in combination with continuous infusion of 5-fluorouracil (5-FU) (4,5). When CDDP-based chemotherapy is administered, antiemetic drugs, such as dexamethasone (DEX), 5- $\mathrm{HT}_{3}$ serotonin receptor antagonists or aprepitant are administered to prevent treatment-associated nausea and vomiting (6). A transient elevation was previously reported in serum Cys $\mathrm{C}$ concentration during the perioperative chemotherapy period in patients with esophageal cancer. We suggested that renal function estimates determined on the basis of serum Cys $\mathrm{C}$ levels during this treatment period might be misleading (7).

To understand the effect of DEX and other drugs in detail, it is crucial to investigate the renal effects associated with serum Cys $\mathrm{C}$ concentration. The aim of this study was to investigate the ability of DEX to induce Cys $\mathrm{C}$ secretion in human cancer cell lines, as well as the effect of CDDP, 5-FU and mifepristone (RU-486) on Cys C secretion.

\section{Materials and methods}

Materials. DEX, 5-FU and CDDP were purchased from Wako Pure Chemical Industries, Ltd. (Osaka, Japan). RU-486 was purchased from Sigma-Aldrich (St. Louis, MO, USA), while 2-(4-iodophenyl)-5-(2,4-disulfophenyl)-2H-tetrazolium, monosodium salt (WST-1) and 1-methoxy-5-methylphenazinium methyl sulfate were purchased from Dojindo Laboratories (Kumamoto, Japan). The remaining reagents were of the highest grade commercially available for biochemical use.

Cell lines and cell culture. The KYSE150 human esophageal squamous cell carcinoma, A549 human non-small cell lung cancer and the Caki-2 human renal carcinoma cell lines were used in this study. KYSE150 and A549 cells were obtained from the Health Science Research Resources Bank (Osaka, Japan), and Caki- 2 cells were obtained from Summit Pharmaceuticals 
International (Tokyo, Japan). KYSE150, and Caki-2 cells were maintained in RPMI-1640 medium (Invitrogen, Carlsbad, CA, USA) with $10 \%$ fetal bovine serum (FBS) (Invitrogen), $100 \mathrm{U} / \mathrm{ml}$ penicillin $\mathrm{G}$ and $100 \mu \mathrm{g} / \mathrm{ml}$ streptomycin (Invitrogen). A549 cells were maintained in Dulbecco's modified Eagle's medium (DMEM; Invitrogen) supplemented with $10 \%$ heat-inactivated FBS, $100 \mathrm{U} / \mathrm{ml}$ penicillin $\mathrm{G}$ and $100 \mu \mathrm{g} / \mathrm{ml}$ streptomycin. The cells were seeded in culture flasks, cultured in a humidified atmosphere of $5 \% \mathrm{CO}_{2}-95 \%$ air at $37^{\circ} \mathrm{C}$, and subcultured with $0.05 \%$ trypsin- $0.02 \%$ EDTA (Invitrogen).

Enzyme-linked immunosorbent (ELISA) assay for Cys C. For the quantification of Cys $C$ protein released from the cells into the culture medium, KYSE150, A549 and Caki-2 cells were seeded in $60-\mathrm{mm}$ dishes at $1 \times 10^{6}$ cells/dish and incubated overnight prior to treatment with each drug for the indicated periods. The final concentrations of the drugs during exposure were $100 \mathrm{nM}, 10,2$ and $1 \mu \mathrm{M}$ for DEX, CDDP, 5-FU and RU-486, respectively. The concentrations of DEX, CDDP and 5-FU were set to mimic clinical conditions (7-9). To examine the inhibitory effects on DEX-induced Cys $\mathrm{C}$ secretion, CDDP, 5-FU and RU-486 were added to the culture medium containing DEX at the abovementioned concentrations for each drug. Control cells were incubated with the culture medium without drugs in each experiment. The culture medium was collected and analyzed with the Quantikine ${ }^{\circledR}$ Human Cystatin C Immunoassay kit (R\&D Systems, Inc., Minneapolis, MN, USA), according to the manufacturer's instructions. The cells were rinsed twice with phosphate-buffered saline (PBS) and harvested with lysis buffer (Sigma-Aldrich). Cell lysates were then vortexed at room temperature for $15 \mathrm{~min}$, and centrifuged at $13,000 \mathrm{x}$ g at room temperature for $15 \mathrm{~min}$. Cell lysates were assayed for total protein levels by using the bicinchoninic acid (BCA) Protein assay kit (Sigma-Aldrich) to adjust Cys C levels. The culture media and cell lysates were stored at $-20^{\circ} \mathrm{C}$ until the ELISA and BCA assays were performed.

WST-1 colorimetric assay. The WST-1 assay was used to evaluate the effect of DEX, CDDP and 5-FU on KYSE150 cell viability (10). The cells were seeded in 96-well plates and pre-cultured for $24 \mathrm{~h}$. The medium was exchanged with one containing each drug at various concentrations. Cells were then incubated for $72 \mathrm{~h}$ at $37^{\circ} \mathrm{C}$. The culture medium was replaced with a medium containing a WST-1 reagent, and $3 \mathrm{~h}$ later the absorbance in the well was determined at $450 \mathrm{~nm}$ with a reference wavelength of $630 \mathrm{~nm}$ using a microplate reader (SpectraFluor ${ }^{\mathrm{TM}}$; Tecan, Maennedorf, Switzerland).

Statistical analysis. The data for Cys C protein release in samples treated with the indicated drugs were expressed as a percentage of the data obtained from the control. Data are presented as the means \pm standard error (SE) of the results of at least three independent experiments. Statistical analyses were performed using the Tukey-Kramer test. $\mathrm{P}<0.05$ (two-tailed) was considered to indicate a statistically significant difference.

\section{Results}

Effect of DEX on Cys C release into culture medium. Fig. 1 shows the Cys C protein release from the KYSE150, A549
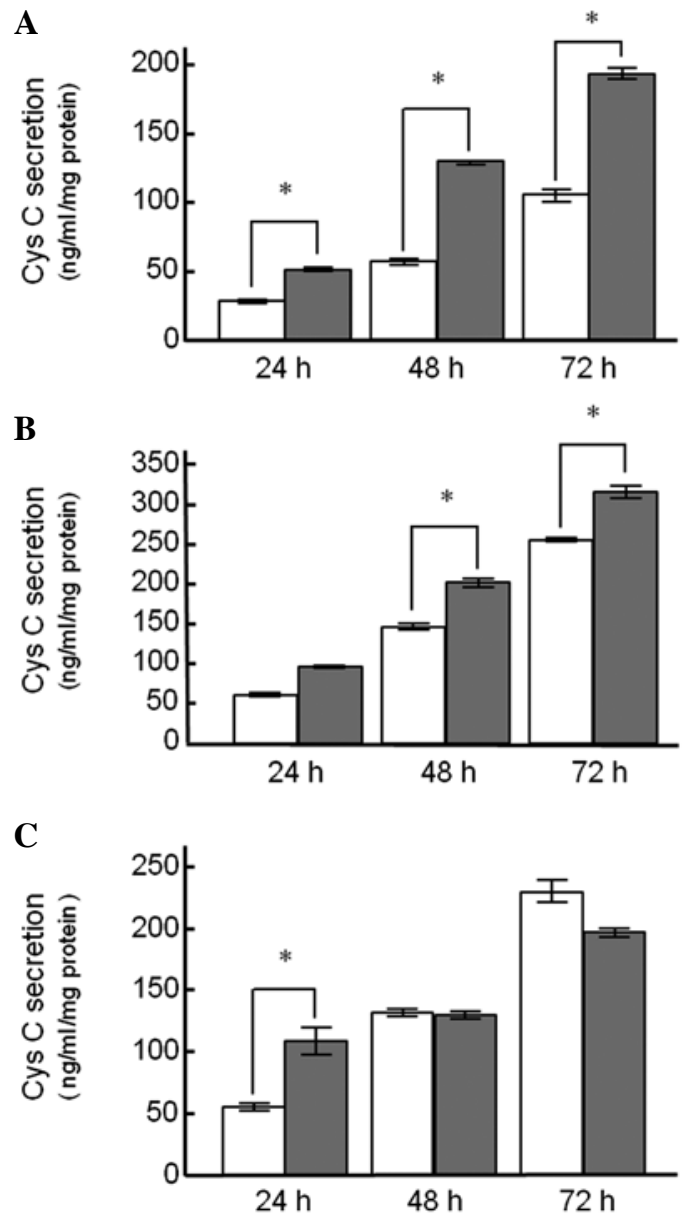

Figure 1. Effect of DEX on Cys $\mathrm{C}$ secretion in the culture medium of (A) KYSE150, (B) A549 and (C) Caki-2 cells is shown. The cells were treated with (dark column) or without (white column) 100 nM DEX for 24 , 48 and $72 \mathrm{~h}$. Each column shows the average and standard error for at least three independent experiments. *Statistically significant difference $(\mathrm{P}<0.05)$ compared to the value in the untreated control cells.

and Caki-2 cell lines treated with DEX. In the cell lines treated with DEX alone, there was a time-dependent increase in Cys $\mathrm{C}$ release into the medium (Fig. 1). Cys $\mathrm{C}$ release from KYSE150 cells treated with DEX for $24 \mathrm{~h}$ was significantly higher compared to the control cells $(50.3 \pm 2.5$ and $27.8 \pm 1.4 \mathrm{ng} / \mathrm{ml} / \mathrm{mg}$ protein, respectively), and a statistically significant difference between DEX-treated and untreated control cells was observed up to $72 \mathrm{~h}$ after treatment (Fig. 1A). Similar findings were also observed in A549 cells (Fig. 1B). However, Cys $\mathrm{C}$ release from Caki-2 cells following treatment with DEX for $24 \mathrm{~h}$ was significantly different from the control group, whereas this difference was not observed for the 48and 72-h treatment groups (Fig. 1C).

Effects of concurrent drug treatment on DEX-induced Cys $C$ release. Cys $\mathrm{C}$ release from KYSE150 cells following treatment with CDDP, 5-FU and RU-486 alone or in combination with DEX was detected (Fig. 2). The cells treated with $100 \mathrm{nM}$ DEX for $72 \mathrm{~h}$ demonstrated a 2.1-fold increase in Cys $\mathrm{C}$ release compared to the control. DEX significantly enhanced Cys $\mathrm{C}$ release up to 1.9 - and 2.0-fold in the presence of $10 \mu \mathrm{MCDDP}$ and $2 \mu \mathrm{M} 5-\mathrm{FU}$, respectively, whereas no such effect was observed in the presence of RU-486 $(1 \mu \mathrm{M})$. Treatment with 5-FU alone significantly 


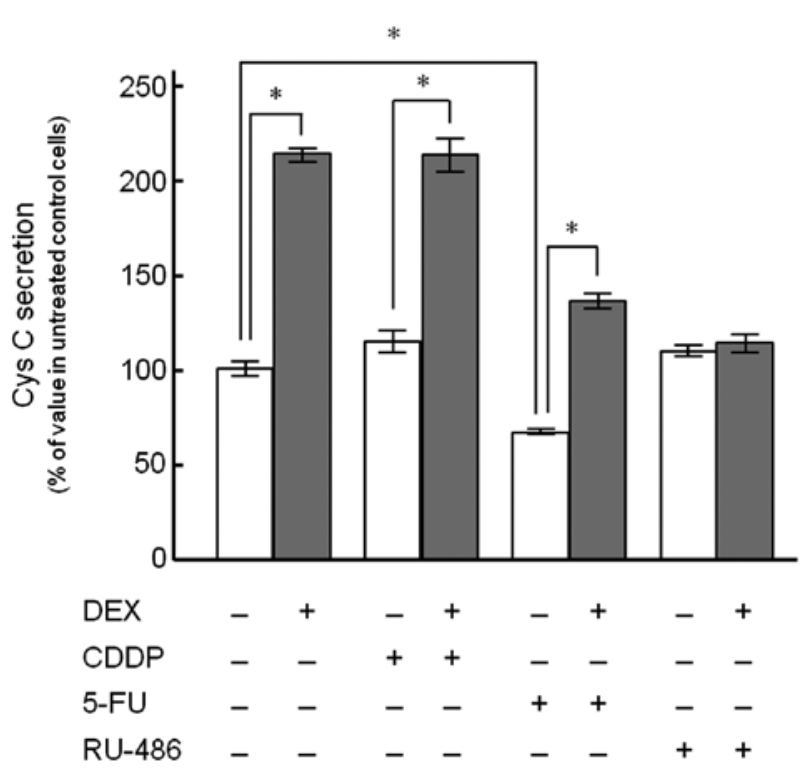

Figure 2. Effects of CDDP, 5-FU and RU-486 alone or in combination with DEX on Cys C secretion into the culture medium of KYSE150 cells are shown. KYSE150 cells were incubated with medium containing CDDP, 5-FU or RU-486 alone (white column), or in combination with DEX (dark column) for $72 \mathrm{~h}$. The final concentrations of the drugs during exposure were $100 \mathrm{nM}$, 10,2 and $1 \mu \mathrm{M}$ for DEX, CDDP, 5-FU and RU-486, respectively. The control cells were incubated with culture medium without drugs in each experiment. Each point shows the average and standard error for at least three independent experiments. "Statistically significant difference $(\mathrm{P}<0.05)$ compared to the value in the untreated control cells.

decreased Cys $C$ release $(66.5 \pm 4.0 \%)$ compared to the control, although CDDP and RU-486 had no significant inductive or suppressive effects when administered alone.

Cell viability analysis. The cytotoxic effect of DEX, CDDP and 5-FU in KYSE150 cells was examined using the WST-1 assay. No cytotoxicity was observed (Fig. 3A) following incubation of KYSE150 cells with DEX at the concentration used in the present experiments $(100 \mathrm{nM})$ for $72 \mathrm{~h}$. KYSE150 cells were also exposed to CDDP or 5-FU (Fig. 3B and C). Each drug reduced cell viability in a concentration-dependent manner, and the number of viable cells at $2 \mu \mathrm{M} 5$-FU and $10 \mu \mathrm{M}$ CDDP was $\sim 60 \%$ of the control cells.

\section{Discussion}

Treatment with DEX induced Cys $\mathrm{C}$ release into the culture medium in the cell lines used in this study (Fig. 1), a fact suggesting that DEX treatment partly contributes to the elevation in serum Cys $\mathrm{C}$ concentration observed during chemotherapy in esophageal cancer patients (7). Co-treatment of DEX with CDDP or 5-FU demonstrated higher extracellular secretion of Cys $\mathrm{C}$, compared to the values observed in the cells treated with the anticancer drug alone, while a synergistic effect between the drugs was not observed (Fig. 2). Regarding the effect of DEX on Cys C production, Bjarnadóttir et al (11) reported that Cys $\mathrm{C}$ expression and secretion from HeLa cells into tissue culture medium increased following treatment with dexamethasone and suggested an association with the Cys $\mathrm{C}$ promoter in tran-
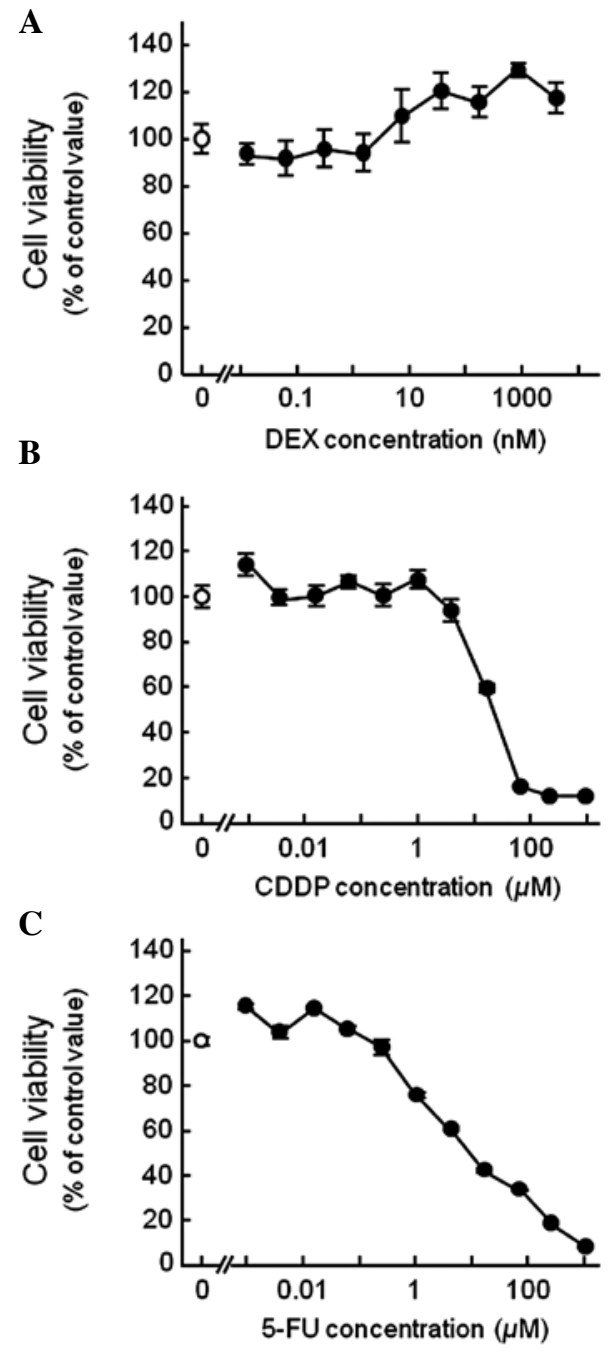

Figure 3. Effects of (A) DEX, (B) CDDP and (C) 5-FU on cell viability in KYSE150 cells are shown. KYSE150 cells were incubated with medium containing DEX (0.01-4,000 nM), CDDP $(0.001-1,024 \mu \mathrm{M})$ or $5-\mathrm{FU}$ $(0.001-1,024 \mu \mathrm{M})$ for $72 \mathrm{~h}$. Cell viability was evaluated using the WST-1 colorimetric assay. Each point shows the average and standard error for at least three independent experiments.

scription of the Cys C gene (11). In this study, we examined the effect of RU-486, a glucocorticoid receptor antagonist, on the enhanced Cys C release from KYSE150 cells induced by DEX. The results showed that RU-486 almost completely suppressed Cys $\mathrm{C}$ release from the cells treated with DEX, probably due to the inhibition of the transcriptional regulation mediated by steroid receptors (Fig. 2). Additionally, CDDP and 5-FU induced apoptosis, whereas the inhibition of apoptosis by DEX promoted proliferation in various established and primary cancer cells (12). The enhanced secretion of Cys C induced by co-treatment with DEX might be correlated with the inhibition of apoptosis as well as the abovementioned transcriptional regulation. Corticosteroids are widely used in cancer as well as immunotherapy, while the potential to underestimate normal renal function during these therapies is of marked importance.

Notably, the secretion of Cys $\mathrm{C}$ was significantly decreased following 5-FU treatment alone compared to the control, whereas no such effect was observed in CDDP treatment 
alone (Fig. 2). The difference in Cys $\mathrm{C}$ secretion is potentially due to a difference in cytotoxicity between CDDP and 5-FU. When assessing the cytotoxic effects of CDDP and 5-FU in KYSE150 cells using the WST-1 assay, treatment with either drug at the concentrations used in the present study reduced cell viability by $\sim 60 \%$ of their respective control values (Fig. 3B and C). The decreased cell viability was not specific to the 5-FU treatment. However, the correlation between cytotoxicity and reduced $\mathrm{Cys} C \mathrm{C}$ secretion was not fully elucidated.

According to the available literature, the Cys $\mathrm{C}$ housekeeping gene is constantly expressed by most nucleated cell types (13), while extracellular cystatins are broadly distributed and detected in most body fluids (14). Cys C is a cysteine protease inhibitor that targets cathepsins (15). Exposure to 5-FU has been reported to result in cleavage of cathepsin B and caspases in human colon carcinoma cell lines, while cathepsin $\mathrm{B}$ activation has been reported to contribute to 5-FU-induced apoptosis (16). Additionally, autophagy is believed to be crucially involved in the suppression of tumorigenesis (17), with 5-FU activating autophagic survival as well as apoptotic cell death (16). Although Cys $\mathrm{C}$ has been demonstrated to affect basal autophagy in neuronal cells under normal culture conditions and its deficiency suppresses autophagy (18), the reduced secretion of Cys $\mathrm{C}$ by 5-FU treatment observed in the present study may contribute to the acceleration of apoptotic cell death. Furthermore, necrosis is a key pathway in non-apoptotic cell death (17). The balance of apoptotic and non-apoptotic cell death varies among types of esophageal and colorectal cancer cell lines $(16,19)$. Additionally, when treated with CDDP and 5-FU, certain cell lines show predominantly apoptotic cell death morphology, while others exhibit predominantly non-apoptotic morphology (19). Although it remains unclear to what extent apoptotic and non-apoptotic cell death were induced in the cells used in the present study, the extent of cytotoxicity might be correlated with the difference in the extracellular secretion of $\mathrm{Cys} \mathrm{C}$ between treatments and cell types. Flow cytometry is required to address these issues in the future.

Circadian variations in physiological and behavioral processes are affected by several endogenous and exogenous factors. DEX has been reported to induce transient changes in the phase of circadian gene expression in peripheral tissues (20), while 5-FU has been demonstrated to have the ability to inhibit oscillation in the expression of clock genes (21). However, to what extent DEX-induced circadian gene expression affects extracellular Cys $\mathrm{C}$ secretion in esophageal cancer patients remains unclear. Moreover, is it not clear to what degree the in vitro reduction in Cys $\mathrm{C}$ secretion induced by treatment with 5-FU contributes to changes in systemic Cys $\mathrm{C}$ concentration. Further investigation concerning the effects of DEX and 5-FU on the cycle of extracellular Cys $\mathrm{C}$ secretion is required to clarify the molecular mechanisms underlying the transient elevation of serum Cys $\mathrm{C}$ concentrations observed in our previous clinical study.

\section{Acknowledgements}

This study was supported in part by a Grant-in-Aid for Young Scientists (B) and a Grant-in-Aid for Encouragement of Scientists from the Japan Society for the Promotion of Science.

\section{References}

1. Filler G,Bökenkamp A,Hofmann W,Le Bricon T, Martinez-Brü C and Grubb A: Cystatin C as a marker of GFR - history, indications, and future research. Clin Biochem 38: 1-8, 2005.

2. Newman DJ: Cystatin C. Ann Clin Biochem 39: 89-104, 2002.

3. Chew JS, Saleem M, Florkowski CM and George PM: Cystatin C - a paradigm of evidence based laboratory medicine. Clin Biochem Rev 29: 47-62, 2008.

4. Ando N, Iizuka T, Ide H, et al: Surgery plus chemotherapy compared with surgery alone for localized squamous cell carcinoma of the thoracic esophagus: a Japan Clinical Oncology Group Study-JCOG9204. J Clin Oncol 21: 4592-4596, 2003.

5. Ando N, Kato H, Igaki H, et al: A randomized trial comparing postoperative adjuvant chemotherapy with cisplatin and 5-fluorouracil versus preoperative chemotherapy for localized advanced squamous cell carcinoma of the thoracic esophagus (JCOG9907). Ann Surg Oncol 19: 68-74, 2012.

6. American Society of Clinical Oncology; Kris MG, Hesketh PJ, Somerfield MR, et al: American Society of Clinical Oncology guideline for antiemetics in oncology: update 2006. J Clin Oncol 24: 2932-2947, 2006.

7. Kume M, Yasui H, Yoshikawa Y, et al: Transient elevation of serum cystatin $\mathrm{C}$ concentrations during perioperative cisplatin-based chemotherapy in esophageal cancer patients. Cancer Chemother Pharmacol 69: 1537-1544, 2012.

8. Miki I, Tamura T, Nakamura T, et al: Circadian variability of pharmacokinetics of 5-fluorouracil and CLOCK T3111C genetic polymorphism in patients with esophageal carcinoma. Ther Drug Monit 27: 369-374, 2005.

9. Nakade S, Ohno T, Kitagawa J, et al: Population pharmacokinetics of aprepitant and dexamethasone in the prevention of chemotherapy-induced nausea and vomiting. Cancer Chemother Pharmacol 63: 75-83, 2008.

10. Takara K, Fujita M, Minegaki T, et al: Treatment scheduledependent effect of 5-fluorouracil and platinum derivatives in colorectal cancer cells. Eur J Pharm Sci 45: 272-281, 2012.

11. Bjarnadóttir M, Grubb A and Olafsson I: Promoter-mediated, dexamethasone-induced increase in cystatin $\mathrm{C}$ production by HeLa cells. Scand J Clin Lab Invest 55: 617-623, 1995.

12. Zhang C, Beckermann B, Kallifatidis G, et al: Corticosteroids induce chemotherapy resistance in the majority of tumour cells from bone, brain, breast, cervix, melanoma and neuroblastoma. Int J Oncol 29: 1295-1301, 2006.

13. Abrahamson M, Olafsson I, Palsdottir A, et al: Structure and expression of the human cystatin C gene. Biochem J 268: 287-294, 1990.

14. Abrahamson M, Barrett AJ, Salvesen G and Grubb A: Isolation of six cysteine proteinase inhibitors from human urine. Their physicochemical and enzyme kinetic properties and concentrations in biological fluids. J Biol Chem 261: 11282-11289, 1986.

15. Grzonka Z, Jankowska E, Kasprzykowski F, et al: Structural studies of cysteine proteases and their inhibitors. Acta Biochim Pol 48: 1-20, 2001.

16. Bijnsdorp IV, Peters GJ, Temmink OH, Fukushima $M$ and Kruyt FA: Differential activation of cell death and autophagy results in an increased cytotoxic potential for trifluorothymidine compared to 5-fluorouracil in colon cancer cells. Int J Cancer 126: 2457-2468, 2010.

17. Mathew R, Karantza-Wadsworth V and White E: Role of autophagy in cancer. Nat Rev Cancer 7: 961-967, 2007.

18. Tizon B, Sahoo S, Yu H, et al: Induction of autophagy by cystatin $\mathrm{C}$ : a mechanism that protects murine primary cortical neurons and neuronal cell lines. PLoS One 5: e9819, 2010.

19. O'Donovan TR, O'Sullivan GC and McKenna SL: Induction of autophagy by drug-resistant esophageal cancer cells promotes their survival and recovery following treatment with chemotherapeutics. Autophagy 7: 509-524, 2011.

20. Balsalobre A, Brown SA, Marcacci L, et al: Resetting of circadian time in peripheral tissues by glucocorticoid signaling. Science 289: 2344-2347, 2000.

21. Terazono H, Hamdan A, Matsunaga N, et al: Modulatory effects of 5-fluorouracil on the rhythmic expression of circadian clock genes: a possible mechanism of chemotherapy-induced circadian rhythm disturbances. Biochem Pharmacol 75: 1616-1622, 2008. 